\title{
Plasma-chemical modification of concrete
}

\author{
Diana Olegovna Bondarenko \\ Department of material science and material \\ technology \\ Belgorod State Technological University named \\ after V.G. Shoukhov \\ BSTU named after V.G. Shoukhov \\ Russia, Belgorod \\ 308012, Kostukov St., 46 \\ di_bondarenko@mail.ru \\ Nadezda Ivanovna Bondarenko \\ Department of glass and ceramics technology \\ Belgorod State Technological University named \\ after V.G. Shoukhov \\ BSTU named after V.G. Shoukhov \\ Russia, Belgorod \\ 308012, Kostukov St., 46 \\ bondarenko-71@mail.ru
}

\author{
Vasiliy Stepanovich Bessmertnyi \\ Department of glass and ceramics technology \\ Belgorod State Technological University named \\ after V.G. Shoukhov \\ BSTU named after V.G. Shoukhov \\ Russia, Belgorod \\ 308012, Kostukov St., 46 \\ vbessmertnyi@mail.ru
}

\author{
Valeria Valerievna Strokova \\ Department of material science and material \\ technology \\ Belgorod State Technological University named \\ after V.G. Shoukhov \\ BSTU named after V.G. Shoukhov \\ Russia, Belgorod \\ 308012, Kostukov St., 46 \\ vvstrokova@gmail.com
}

\begin{abstract}
Plasma chemical modification (PCM) improves chemical resistance of a glazed decorative coating and expands opportunities for designing various types of the decoration of concrete. However, PCM exposes the material to a significant thermal shock that leads to dehydration of hydrosilicates in the cement matrix followed by loss of strength of the concrete coating. This results in a reduction in the service characteristics of the concrete protective and decorative layer such as adhesion strength and freeze-thaw resistance and shortens the coating durability. Therefore, the improvement of the PCM method is a hot topic of the study and it is one of the most effective and modern technologies, which will result in enhancement of serviceability of concrete with the glazed decorative coating.
\end{abstract}

This study investigated the effect of incorporation of calcium aluminate cement as a silicon-based intermediate layer between the glazed decorative layer and the concrete surface.

The study demonstrated that the calcium aluminate cement intermediate layer after plasma chemical modification was dehydrated. Based on mineral composition and structural analysis, the dehydrated layer was visually divided into three zones: the upper dense layer; an intermediate layer with micro cracks; and the bottom dense layer. The microstructure of the dehydrated zone is represented by small non-developed microcracks less than $50 \mu \mathrm{m}$. Magnesium spinel was the main crystal phase in a calcium aluminate cement matrix. The dense dehydrated zone had a shell-like fracture, which is typical for spinel with imperfect cleavage.

This study developed a glazed decorative coating and a protective calcium aluminate cement-based intermediate layer with the adhesion strength of 4.1 MPa and freeze-thaw resistance of more than 50 cycles that exceed service characteristics of concrete with the coatings using other materials.

Keywords: Plasma-chemical modification, protectivedecorative coating, plasma jet, face layer.

\section{INTRODUCTION}

The implementation of the Presidential program "Affordable Housing for Russian Citizens" considers an increase in the production of wall building materials, particularly concrete products. Protective and decorative coatings on concrete significantly enhance the architectural and artistic merits of buildings and structures.

One of the most effective modern technologies is the plasma-chemical modification of protective-decorative coatings applied on concrete. To expand the color characteristics and minimize dehydration, various fillers made of ceramics, glass, expanded clay, chamotte, waste from the mining or metallurgical industry, etc. are used 
before the plasma-chemical modification in the molding of concrete "face down" or "face up" [1-9]. Protectivedecorative coatings on concrete have relatively low quality indicators $[10,11]$. The adhesion strength of the coating with the substrate does not exceed $1 \mathrm{MPa}$ and is $0.1-0.2$ $\mathrm{MPa}$, and the freeze-thaw resistance does not exceed 15-30 cycles.

It is proposed to use alumina cement as the basis of a protective and decorative coating, and as a filler - certain fractions of colored container glasses and the breakages of sanitary ceramics. According to a number of authors, when plasma reflows of concrete products are processed, the surface treated by the high-temperature jet is heated to a depth of several millimeters [10-14]. In this regard, the compositions of mixtures based on alumina cement have been developed for preliminary application to the front surface of concrete.

\section{Results and discussions}

To study the effect of PCM on the formation and accumulation of fusion, samples of alumina cement were made with a size of $20 \times 20 \times 20 \mathrm{~mm}$. After hardening for 3 days, samples were reflowed at the speed of the plasma jet passing through the face at a rate of $2 \mathrm{~mm} / \mathrm{s}$. The hightemperature source was the plasma plant "Gorynych" with a plasma jet temperature of $6000 \mathrm{~K}$. The plasma torch's operation parameters were 6 amperes, 140-160 volts (Fig. $1)$.
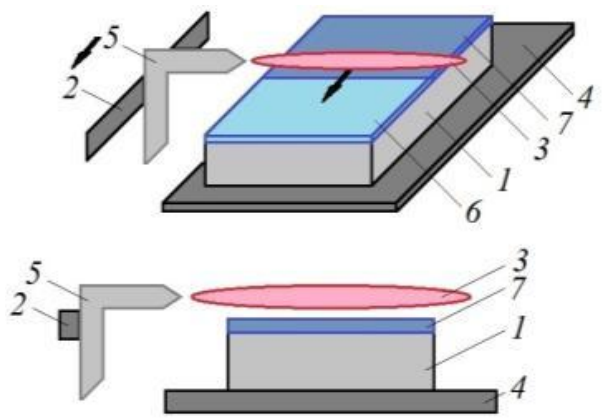

Fig. 1. Stand for plasma-chemical modification: 1 - sample; 2 - moving platform with the plasma unit; 3 - plasma jet; 4 - stand for installation of the sample; 5 - plasma plant "Gorynych"; 6 - unfused protective-decorative coating; 7 - fused protective and decorative coating

The average chemical composition of the glass determined by the X-ray fluorescent method is presented in Table I and differs from the chemical composition of the alumina cement. The change in the chemical composition of the amorphous phase is associated with the processes of evaporation and thermal diffusion.

TABLE I. CHEMICAL COMPOSITION OF THE AMORPHOUS PHASE AFTER PLASMA-CHEMICAL MODIFICATION

\begin{tabular}{|c|c|c|c|c|c|c|c|}
\hline \multicolumn{7}{|c|}{ Chemical composition, mass. \% } \\
\hline $\mathbf{A l}_{\mathbf{2}} \mathbf{O}_{\mathbf{3}}$ & $\mathbf{C a O}$ & $\mathbf{M g O}$ & $\mathrm{SiO}_{\mathbf{2}}$ & $\mathbf{V}_{\mathbf{2}} \mathbf{O}_{\mathbf{5}}$ & $\mathbf{F e}_{\mathbf{2}} \mathbf{O}_{\mathbf{3}}$ & $\mathbf{M n O}$ & $\mathbf{T i O}_{\mathbf{2}}$ \\
\hline 64.81 & 17.02 & 16.01 & 2.44 & 0.41 & 0.17 & 0.08 & 0.06 \\
\hline
\end{tabular}

The thickness of the fused zone is affected by the speed of passage of the plasma jet over the face of the concrete. With a decrease in the reflow rate of the sample from 20 to
$10 \mathrm{~mm} / \mathrm{s}$, a continuous glassy coating with a thickness of $500 \pm 25 \mu \mathrm{m}$ was formed on their front surface, and $2500 \pm$ $25 \mu \mathrm{m}$ at a velocity of $2 \mathrm{~mm} / \mathrm{s}$ (Fig. 2).

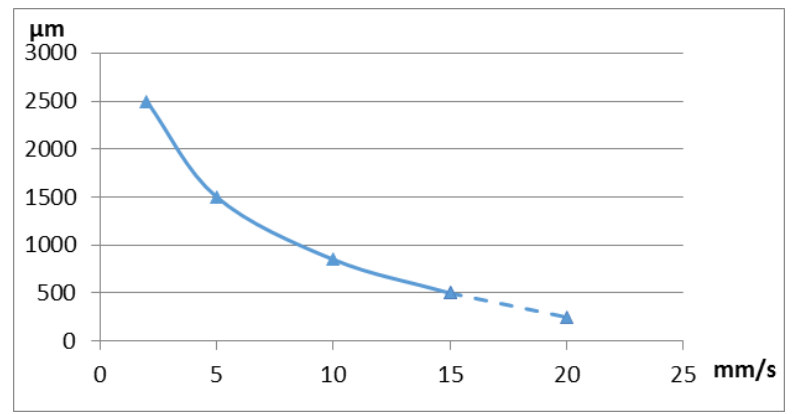

Fig. 2. Graph of the dependence of the thickness of the reflow zone on the face of the hydrated alumina cement matrix from the speed of passage of the plasma jet:_ continuous coating; - - - discontinuous coating

As can be seen from Fig. 2, with an increase in the rate of the plasma jet passing over the face of the sample at a rate of more than $15 \mathrm{~mm} / \mathrm{s}$, there was no formation of a continuous coating on the front surface of samples from alumina cement.

At a plasma flow rate of $2 \mathrm{~mm} / \mathrm{s}$, the temperature of the fusion heating and the kinetics of its cooling were determined (Fig. 3). For this purpose, an optical pyrometer and a platinum-platinum-rhodium thermocouple were used.

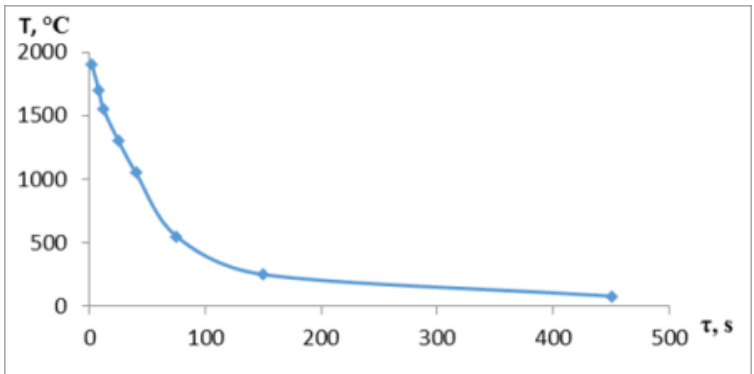

Fig. 3. A graph of cooling kinetics of the fused zone on the sample of alumina cement at a plasma flow rate of $2 \mathrm{~mm} / \mathrm{s}$

As can be seen from Fig. 3, heating to $2000{ }^{\circ} \mathrm{C}$ occurred almost in fractions of a second. Cooling of the facial zone to $300{ }^{\circ} \mathrm{C}$ occurred after 5 minutes.

The structure and distribution of elements of the fused layer of dehydrated alumina cement are presented in Figures 4,5 . 


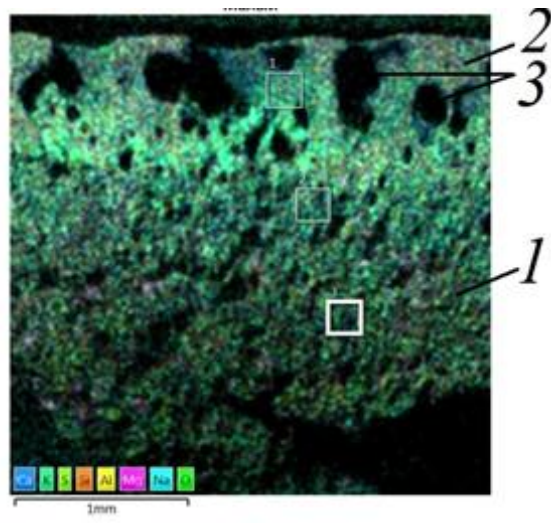

Fig. 4. The tested sample of aluminous cement fused by a plasma jet: $1-$ matrix of alumina cement; 2 - fused zone; 3 - bubbles
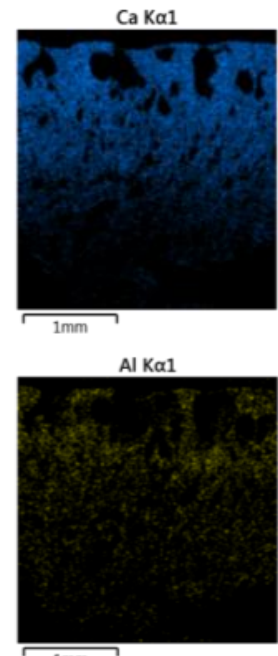

$1 \mathrm{~mm}$
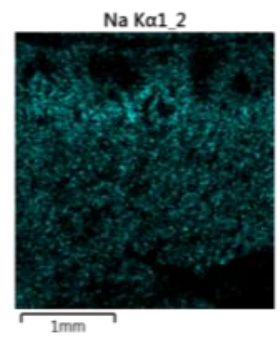

Si $K a 1$
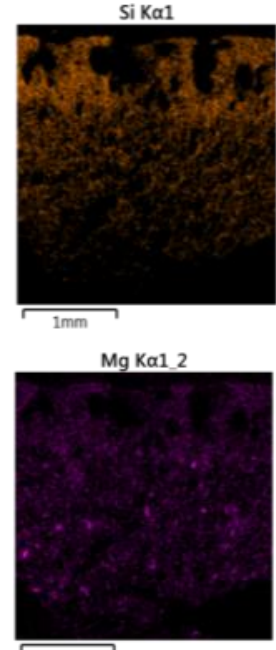
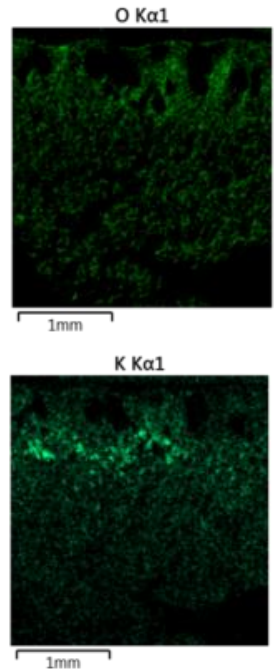

$\mathrm{Fe} K \alpha 1$

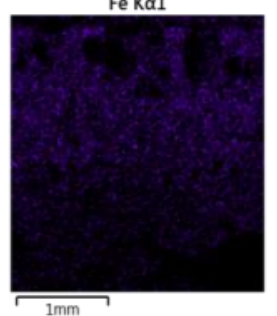

Fig. 5. Distribution of elements $\mathrm{Ca}, \mathrm{Si}, \mathrm{O}, \mathrm{Al}, \mathrm{Mg}, \mathrm{K}, \mathrm{Na}, \mathrm{Fe}$ by the thickness of the fused, intermediate and deep layer of concrete

The melted zone was examined by X-ray phase analysis (Fig. 6).

As can be seen from Fig. 6, the fused layer is represented by an amorphous phase. The composition of the amorphous phase is represented by $\mathrm{Mg}-\mathrm{Ca}-\mathrm{Al}$ glass.

The microstructure of the glass phase is shown in Fig. 7; the fusion is not homogenized and had, in addition to gas inclusions, an area of microinhomogeneity.

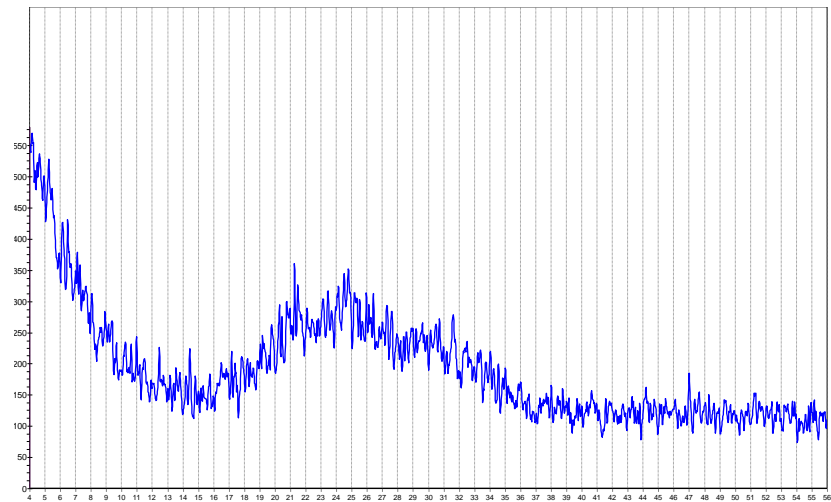

Fig. 6. A powder x-ray diffractogram of the fused zone

In the investigated protective and decorative coating below the fused zone, there is a zone of dehydrated alumina cement with the different phase composition, macro- and microstructure (Fig. 8).

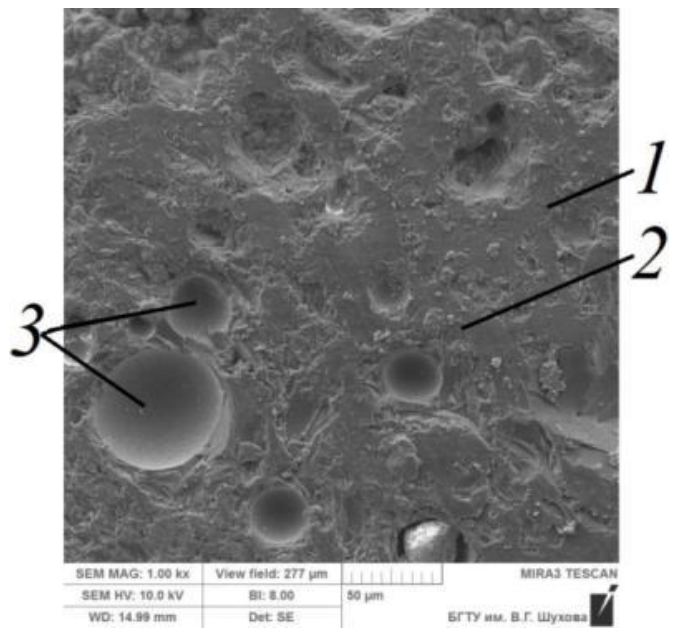

Fig. 7. A microstructure of the glass phase: 1 - matrix of glass; 2 - areas of heterogeneity; 3 - gas inclusions

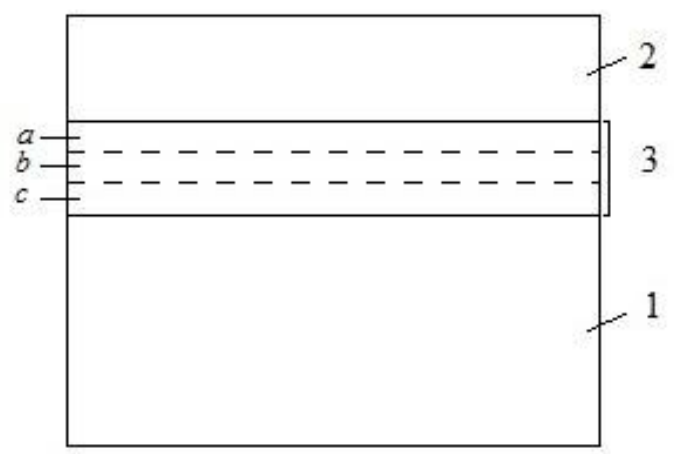

Fig. 8. A structure of the surface layer sample after plasma-chemical modification: 1 - matrix of the sample with the size of $20 \times 20 \times 20 \mathrm{~mm} ; 2-$ amorphous zone; 3 - dehydrated zone: a - upper dense layer; $\mathrm{b}$ - medium microfractured; $\mathrm{c}$ - lower dense layer

The phase composition of the dehydrated zone (3) and its sections: $a, b, c$ was studied by X-ray phase analysis. The phase composition of the upper dense layer (a) is represented by calcium monoaluminate and spinel (Fig. 9). 
The composition of the spinel $\mathrm{Mg}_{0,4} \mathrm{Al}_{2,4} \mathrm{O}_{4}$ was identified by the magnitude of the interplanar distances.

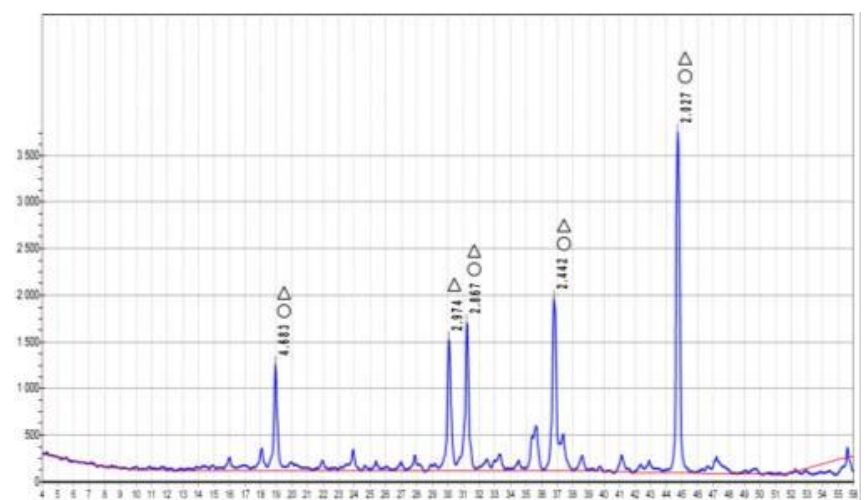

Fig. 9. Powder x-ray diffractogram of dehydration zone (a - upper dense layer): $\odot-\mathrm{MgAl}_{2} \mathrm{O}_{4} ; \Delta-\mathrm{CaAl}_{2} \mathrm{O}_{4}$

In this layer (a) there were no microfractures (Fig. 10).

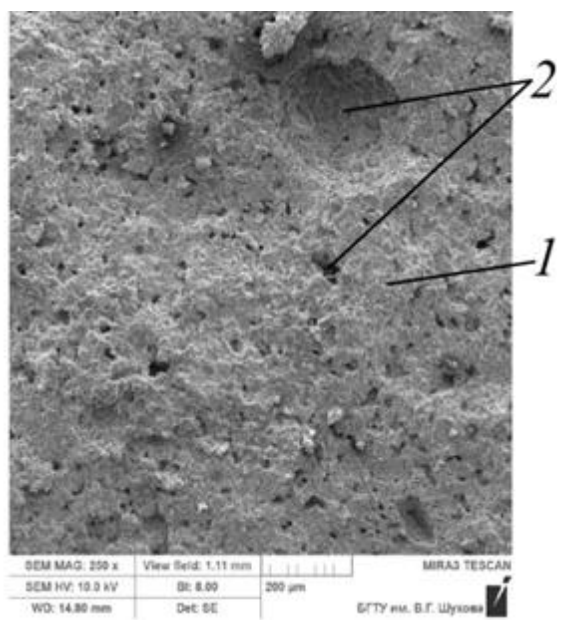

Fig. 10. Microstructure of the dehydration zone (a - upper dense layer): $1-$ crystalline phase; 2 - pores

The phase composition of layer (b) is represented by spinels with different substitution of the crystallographic positions: $\quad\left(\mathrm{Mg}_{0,68} \mathrm{Al}_{0,32}\right) \cdot\left(\mathrm{Al}_{0,84} \mathrm{Mg}_{0,16}\right)_{2} \mathrm{O}_{4} \quad$ and $\left(\mathrm{Mg}_{0,68} \mathrm{Al}_{0,32}\right) \cdot\left(\mathrm{Al}_{0,68} \mathrm{Mg}_{0,32}\right)_{2} \mathrm{O}_{4}$ and calcium monoaluminate (Fig. 11).

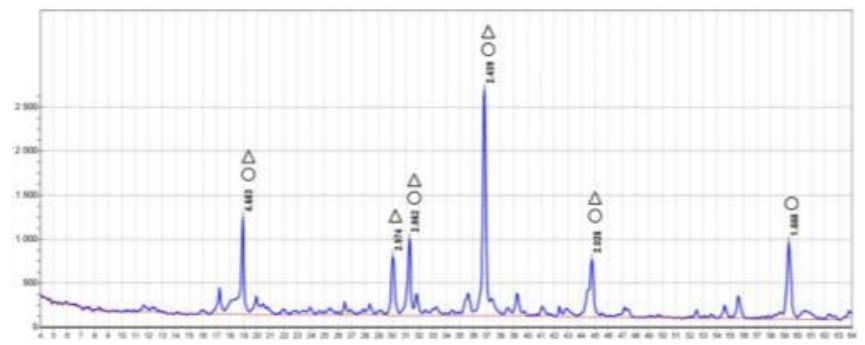

Fig. 11. A powder $\mathrm{X}$-ray diffractogram of the dehydration zone in a sample of alumina cement (layer b): $\odot-\mathrm{MgAl}_{2} \mathrm{O}_{4} ; \Delta-\mathrm{CaAl}_{2} \mathrm{O}_{4}$

Spinels with different substitution of crystallographic positions were identified by the magnitude of interplanar distances using the computer program "Crystallography" (Table II).
TABLE II. SPINELS IDENTIFIED IN THE PROTECTIVE-DECORATIVE COATING AFTER PCM

\begin{tabular}{|c|c|c|c|c|c|c|c|c|}
\hline Compositions & 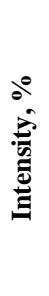 & 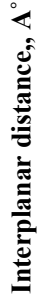 & 胥 & 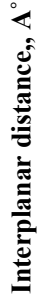 & 莺 & 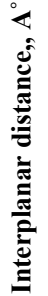 & $\frac{80}{3}$ & 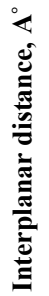 \\
\hline \multirow{2}{*}{$\mathrm{MgAl}_{2} \mathrm{O}_{4}$} & 10 & 2.4 & 6 & 2.0 & 4 & 1.5 & 3 & 4.6 \\
\hline & 0 & 37 & 5 & 2 & 5 & 55 & 5 & 6 \\
\hline \multirow{2}{*}{$\mathrm{Mg}_{0,4} \mathrm{Al}_{2,4} \mathrm{O}_{4}$} & 10 & 2.4 & 3 & 2.0 & 1 & 1.5 & 5 & 4.6 \\
\hline & 0 & 39 & 2 & 22 & 7 & 57 & 0 & 7 \\
\hline \multirow{2}{*}{$\begin{array}{l}\left(\mathrm{Mg}_{0,68} \mathrm{Al}_{0,32}\right)\left(\mathrm{Al}_{0,84} \mathrm{M}\right. \\
\mathrm{g}_{0,16)_{2} \mathrm{O}_{4}{ }^{*}}\end{array}$} & 10 & 2.4 & 5 & 2.0 & 4 & 1.5 & 3 & 4.6 \\
\hline & 0 & 38 & 0 & 21 & 0 & 56 & 0 & 68 \\
\hline \multirow{2}{*}{$\mathrm{MgAl}_{1,94} \mathrm{Fe}_{0,1} \mathrm{O}_{4}$} & 10 & 2.4 & 5 & 2.0 & 4 & 1.5 & 4 & 4.6 \\
\hline & 0 & 39 & 5 & 22 & 4 & 57 & 8 & 7 \\
\hline
\end{tabular}

In the layer (b) (Fig. 12), mixed spinels were formed under the action of a plasma jet.

As can be seen from Fig. 12 (a, b), in this layer in addition to the crystalline phase and pores, there was an insignificant number of undeveloped microfractures, the size of which did not exceed $50 \mu \mathrm{m}$.

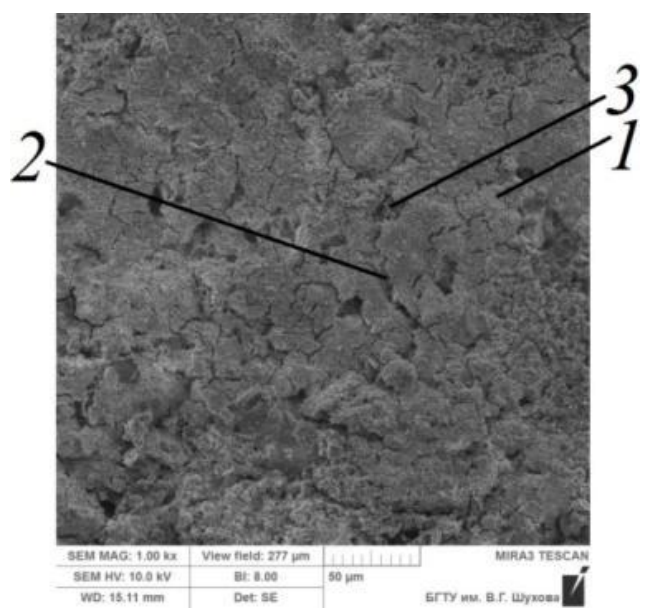

a)

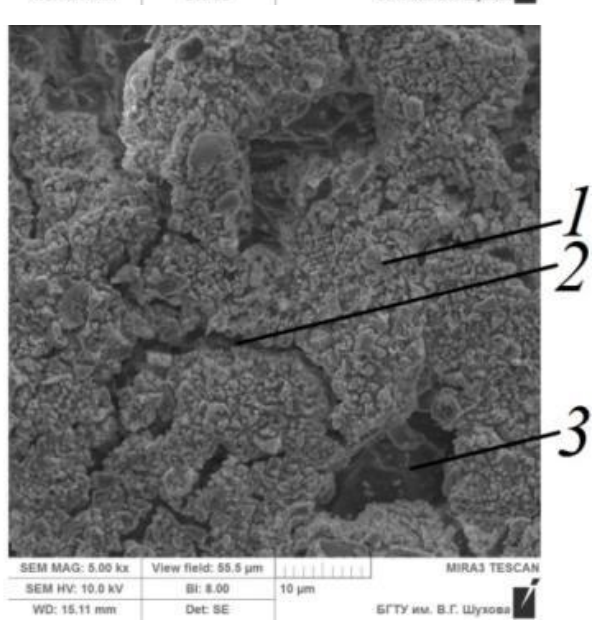

b)

Fig. 12. A microstructure of the dehydrated layer (b): $1-$ matrix of alumina cement; 2 - fractures; 3 - pores 
As it was shown by the X-ray phase analysis of the lower layer (c), the main phases are calcium monoaluminate and spinel of composition $\mathrm{MgAl}_{1,9} \mathrm{Fe}_{0,1} \mathrm{O}_{4}$. The microstructure of the layer (c) is shown in Fig. 13 (a, b, c).

The crystalline phase has a conchoidal fracture, which is typical of spinel having imperfect cleavage.

The formation of spinels contributed to the sintering and consolidation of the fused layer and, as a consequence, to an increase in such operational parameters as adhesion strength and freeze-thaw resistance.

a)

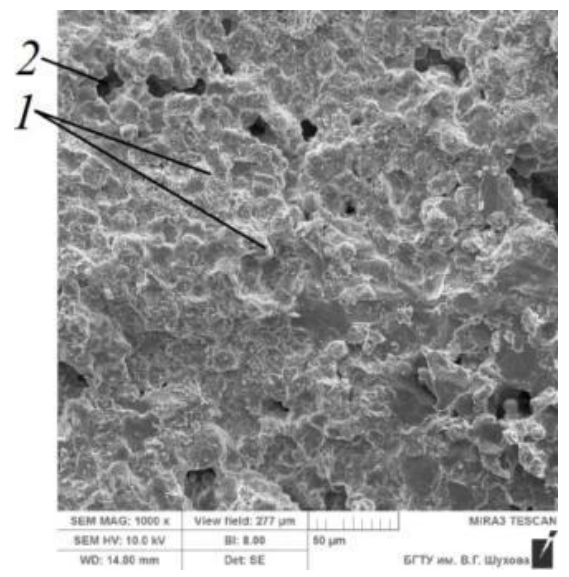

b)

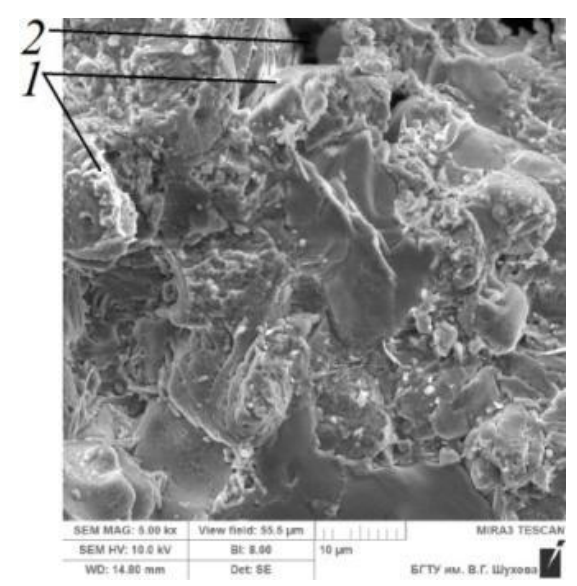

c)

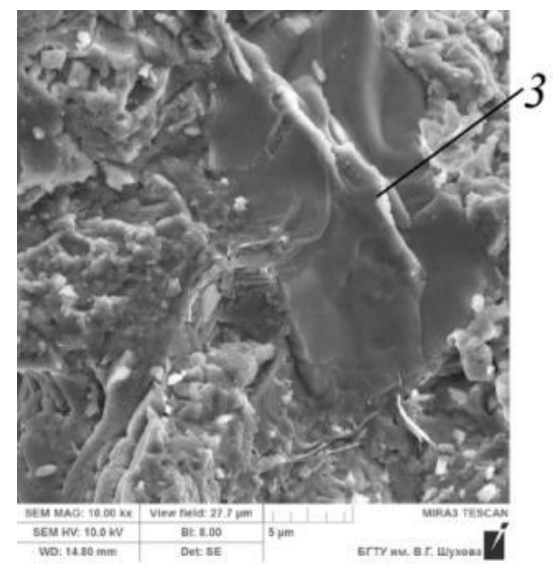

Fig. 13. A microstructure of the dehydrated layer (c): 1 - crystals; $2-$ pores; 3 - elements of a conchoidal fracture

\section{Conclusion}

The conducted research made it possible to establish regularities in the formation of the structure of protectivedecorative coatings on concrete using color metal salts. Using a plasma jet, it is possible to regulate the medium that will make it possible to expand the color scale of coatings.

High microhardness of coatings obtained after plasmochemical modification of fine-grained concrete will improve its resistance to scratching and possible shock loads during operation. This will increase the reliability and durability of fine-grained concrete with protectivedecorative coatings.

\section{Acknowledgment}

The work is realized with the financial support of the Grant of the President for scientific schools, № NSh2724.2018.8, using equipment of High Technology Center at BSTU named after V.G. Shoukhov

\section{References}

[1] G. Bolelli, V. Cannillo, T. Lusvarghi, T. Manfredini, C. Siligardi, C. Bartuli, A. Loreto, T. Valente, "Plasma - sprayed glass-ceramic coatings on ceramic tiles:nicrostructure, chemical resistanace and mechanical proprties", Jonrnal of the Eukopean Ceranic Sociaty, vol. 25 (11), pp. 1835-1853, 2005.

[2] V.S. Bessmertnyi, A.V. Simachev, N.M. Zdorenko, I.V. Rozdol'skaya, N.I. Min'ko, N.I. Bondarenko, D.O. Bondarenko, "Evaluation of the competitiveness of wall building materials with glassy protective-decorative coatings obtained by plasma fusing", Glass and Ceramics, vol. 72 (1-2), pp. 41-46, May 2015.

[3] Yu.A. Shchepochkina, M.V. Akulova, S.V. Fedosov, "Use of waste in a vitreous coating for brick", Glass and Ceramics, vol. 57 (11-12), pp. 389, November 2000 .

[4] M.V. Akulova, Yu.A. Shchepochkina, "New low-melting glazes for concrete", Glass and Ceramics, vol. 56 (3-4), pp. 127-128, March 1999.

[5] S.V. Fedosov, M.V. Akulova, Yu.A. Shchepochkina, "Tinting glaze with iron-containing compounds on nonfired inorganic materials", Glass and Ceramics, vol. 62 (1-2), pp. 30-31, January 2005.

[6] D.O. Bondarenko, N.I. Bondarenko, V.S. Bessmertnyi, N.M. Burlakov, "Plasma-chemical modification of concrete processed by colorific metal salts", Advances in Engineering Research, vol. 133, pp. 128-134, November 2017.

[7] O.G. Volokitin, N.K.Skripnikova, O.G. Volokitin, V.V. Shekhovtsov, "Application plasma technologies for modification of the surface various construction materials", Actual problems of modernity, vol. 1 (11), pp. 144-149, 2016.

[8] V.A. Vlasov, G.G. Volokitin, N.K. Skripnikova, O.G. Volokitin, V.V. Shekhovtsov, "Surface modification of materials kilns lowtemperature plasma", News of higher educational institutions, vol. 58 (9-2), pp. 84-87, 2015.

[9] Yu.A. Shchepochkina, M.V. Akulova, S.V. Fedosov, "Use of waste in a vitreous coating for brick", Glass and Ceramics, vol. 57 (11-12), pp. 389, 2000.

[10] Yu.M. Bazhenov, S.V. Fedosov, Yu.A. Shchepochkina, M.V. Akulova, High-temperature finishing of concrete with vitreous coatings, Moscow: ASV, 2005.

[11] S.V. Fedosov, M.V.Akulova, , Yu.A. Shchepochkina, E.D. Podlozny, N.N. Naumenko, Plasma reflow of building composites, Moscow: ASV, Ivanovo: IGASU, 2009.

[12] S.V. Fedosov, M.V. Akulova, Plasma metallization of concretes, Moscow: ASV, 2003. 
[13] G.G. Volokitin, N.K. Skripnikova, O.G. Volokitin, V.V. Shekhovtsov, "Development of plasma technology for building industry", Actual problems of modernity, vol. 1 (15), pp. 150-154, 2017.

[14] Yu.E. Gromov, V.P. Lechepekov, G.V. Severinov, Industrial finishing of building facades, Moscow: Stroiizdat, 1980. 